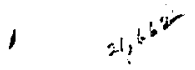

\title{
A METHOD OF EVALUATING SCANNING EFFICIENCY FOR QUARK-LIKE (PSEUDO) TRACKS IN A FLAT-GEOMETRY CLOUD CHAMBER
}

\author{
R. D. Ernst:
}

March 27, 1973

Prepared for U.S. Atomic Energy Commission under contract No. W-7405-Eng-48
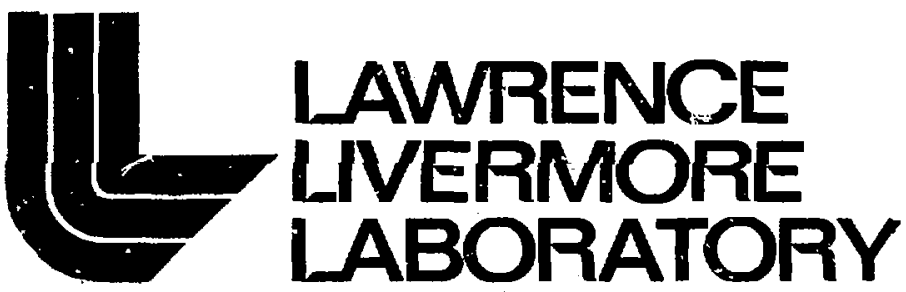

University of California/Livermore 
HOTICE

This refort was prepured as an scrownt of wolk sponered by the United States Coverment. Hiller the United States tor the United Stutes Alomic Enery Commition, nor any of inefr eqployets, nor any of their conirseton, subesntpetors, or itxi:

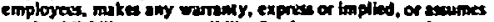

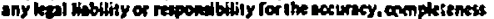

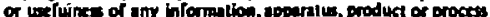

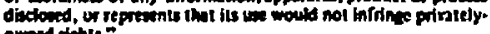
ouned tifhte"

Printed in the United States of America Available from

National Technical Information Service

U. S. Department of Commerce 5285 Port Royei Road

Springfield, Virginia 22151

Price: Printed Copy \$_*; Microfiche $\$ 0.95$

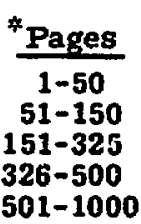

NTIS

Selling Price

$\$ 4.00$

$\$ 5.45$

$\$ 7.60$

$\$ 10.60$

$\$ 13.60$ 
TID-4500, UC-34

Physics

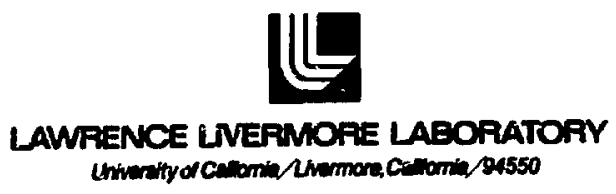

UCRL-51369

\title{
A ARETHOD OF EVALUATING SCANNING EFFICIENCY FOR QUARK-LIKE (PSEUDO) TRACKS IN A FLAY-GEOMETRY CLOUD CHAMBER
}

\author{
R. D. Ernst
}

MS. date: March 27, 1973

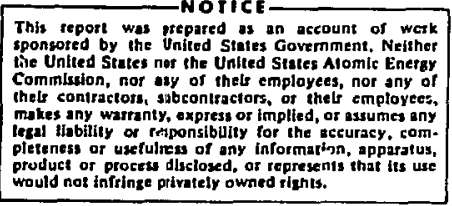




\section{Contents}

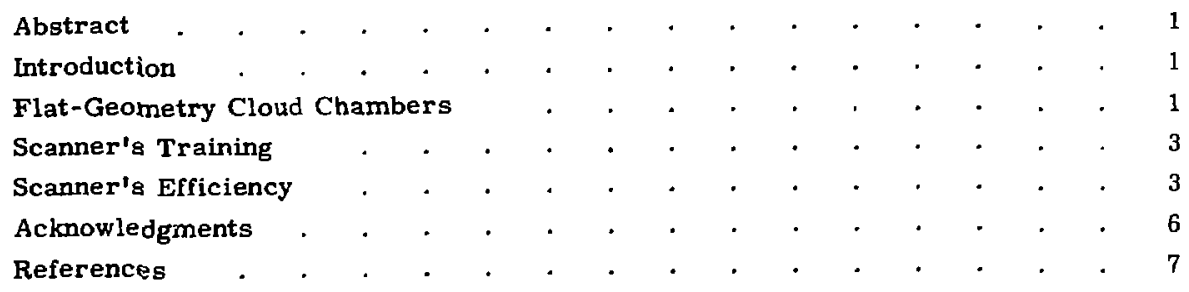




\title{
A METHOD OF EVALUATING SCANNING EFFICIEINCY FOR QUARK-LIKE (PSEUDO) TRACKS IN A FLAT-GEOMETRY CLOUD CHAMBER
}

\begin{abstract}
This paper is a supplement to "Pseudo Cloud Chamber Tracks and Their Uses" published April 13, 1972 (UCRL-51214), and deals with further uses of artificially produced cloud-chamber tracks used in

the quark quest. These tracks were used to train scanners to look for $1 / 9$ normaldensity tracks, and to measure a scanner's efficiencies for finding $1 / 9$ and lower $(1 / 12$, $1 / 18$, and $1 / 36$ ) normal-density tracks.
\end{abstract}

\section{Introduction}

The work reported herein is a continuation of an earlier study employing artificial cloud chamber tracks ${ }^{1}$ which wes a part of the quark quest. ${ }^{2,3}$ To make it easier to find low-density tracks the cloud chambers were turned over on their sides, making the thin dimension of the photographed volume vertical, a configuration which we called "flat geometry."

The pseudo tracks for the flat-geometry chambers were developed in April 1971; first, as a feesibility study to determine the ability of the scanners to see $1 / 9$ quark tracks in this geometry; second, to educate the scanners in finding $1 / 9$ quark tracks; and third, to determine the efficiency of the scanners for finding such tracks.

Following the feasibility studies, the scanner's education and efficiency studies were begun. The determination of the scanner's efficiencies was a long-term project extending from April 1971 io December 1972.

After the efficiency program had been running for about a year, an interest developed in how light a density track the scanners could see. Therefore, pseudo tracks having lensities lower than $1 / 9$ were developed $(1 / 12,1 / 18,1 / 36)$. This program started in July 1972 and was completed in December 1972. This report summarizes the results of these programs.

\section{Flat-Geometry Cloud Chambers}

The flat-geometry chambers had their anique problems since tne apparent density and length of the tracks depend on the angle in which the particles go trrough the chambers. The scanners looked at projected images of foreshortened tracks. Therefore, they had to be aware of the length-to-density ratio; the shorcer the track, the higher the density (Fig, 1). Table 1 shaws the pseudo tracks needed 


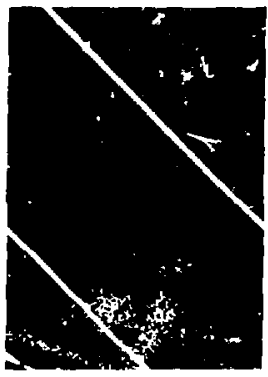

(a)

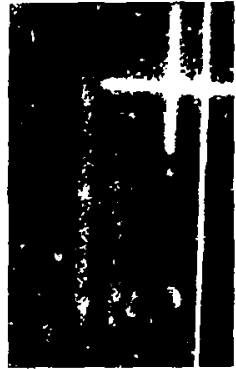

(b)

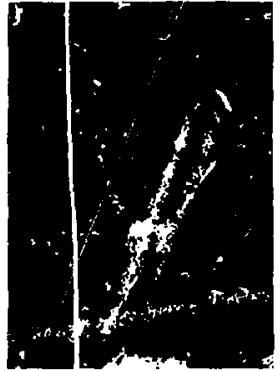

(c)

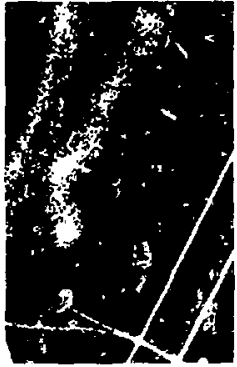

(d)

Fig. 1. Various light density pseudo tracks that were picked up by our acanners in normal scanning. (a) $1 / 9$ at $40^{\circ}$, (b) $4 / 9$ at $20^{\circ}$, (c) $1 / 9$ at $15^{\circ}$ and a normal track at $\sim 20^{\circ}$, and (d) $1 / 12$ at $10^{\circ}$. Note the length-tr-density ratio of the $1 / 9$ tracks.

Table 1. Template guide for superimposing pseudo tracks.

\begin{tabular}{lccccc}
\hline $\begin{array}{c}\text { Zenith } \\
\text { angle } \\
\text { (deg) }\end{array}$ & $\begin{array}{c}\text { Density of } \\
\text { projected } \\
\text { pseudo track }\end{array}$ & $\begin{array}{c}\text { Drops/cm } \\
\text { needed }\end{array}$ & $\begin{array}{c}\text { Drops/cr } \\
\text { in template } \\
\text { used }\end{array}$ & $\begin{array}{c}\text { Total } \\
\text { track } \\
\text { length } \\
\text { (cm) }\end{array}$ & $\begin{array}{c}\text { In-Focus } \\
\text { length } \\
\text { (cm) }\end{array}$ \\
\hline $10^{\circ}$ & $4 / 9$ & 191 & - & 1.6 & 1.3 \\
& $1 / 9$ & 47 & 48 & 1.6 & 1.3 \\
& $1 / 18$ & 24 & 20 & 1.6 & 1.3 \\
$20^{\circ}$ & $4 / 9$ & 97 & 110 & 3.3 & 2.8 \\
& $1 / 9$ & 25 & 20 & 3.3 & 2.8 \\
& $1 / 18$ & 12 & 12 & 3.3 & 2.8 \\
$30^{\circ}$ & $4 / 9$ & 67 & 65 & 5.3 & 4.4 \\
& $1 / 9$ & 16 & 20 & 5.3 & 4.4 \\
& $1 / 18$ & 8 & 7 & 5.3 & 4.4 \\
\hline
\end{tabular}

to be placed on the top glass of the clond chamber, such that the density is correct for the projection of quark tracks going through the chambers in the flat geometry. The first column is the zenith angle, the second column is the type of track needed. The third column is the drops $/ \mathrm{cm}$ that should be placed on the top glass to represent that type of track, the fourth column is the template that was chosen that matched the best. The fifth and sixth columns are the two different lengths used to make the tracks appear as if they were going through the regions of of good focus and illumination and poor focus and illunination. 


\section{Scanner's Training}

The technirue used for training the scal ers for finding $1 / 9$ quark tracks was as follows: First, a number of tracks with zenith angles ranging from $10^{\circ}$ to $40^{\circ}$ were superimposed on cloud chamber pictures and scanned. The scanners would mark all the light-density tracks they fourd. Next, the tracks that were missed were shown to the scanners. This would show the scanners that there were light-density tracks to be found and what they looked like in the chamber. After this was done, noore light-density tracks were put on chambers at random for monitoring the scanner's abilities to find -ich tiacks.

Any problems the scanners had were brought to their aitention. It was noticed while the scanners vere being trained to see light-density tracks that once they understood what to lool for, the scanning efficiency increased considerably. Most of the time during "proriuction" scanning, the scanners were not made aware of the tracks they missed. Figur' 2 (a) plots the efficiency of two consecutive scanners in finding $1 / 9$ normal tracks (and 1/i2, 1/18 and 1/36 normal tracks) plotted versus time, and Fig. 2(b) nlots chamber weeks * scanned vershs time. A total of 305 chamber weel:s was scarned. When the curve in Fig. 2(a) is multiplied by the percent of film scanned in Fig. 2(b), the net "effective eificiency" is obtained. inis is described later in the text.

\section{Scanner's Efficiency}

The scanner's efficiency was checked using 24 different light-density tracks representing densities from $4 / 9$ to $1 / 25$ of normal, and at zenith angles from $10^{\circ}$ to $35^{\circ}$ (Fig. 3). The number of times a track of a given angle was used was determined by the likelihood that cosmic-ray tracks would come into the chambers at such angles. ${ }^{1}$ The total number of tracks used was 163 , and 7 was the average number of times any one track was used. But 3 was the average number of times the scanner found any one track. The tracks were superimposed on five different chambers, with three out of the five champers having cameras set 24.5 in. from the center of the chamber and the other two chambers having cameras set 28.5 in. from the center. One of the chambers was inder 4 in. of lead; $7 \%$ of the $1 / 9,25 \%$ of the $1 / 12,20 \%$ of the $1 / 18$, and $12 \%$ of the $1 / 36$ iracks were superimposed on the lead-covered chamber.

The emphasis was put on the $1 / 9$ pseudo tracks. Nine different tracks were made up. The total number of $1 / 9$ tracks exposed on the chambers was 58 .

To get the efficiency for finding lightdensity pseudo tracks normalized into a meaningful value that would show our ability for finding quark-like tracks in a cosmic-ray shower, we had to take into account the angle of the tracks and the amount of film scanned under a given efficiency.

\footnotetext{
* Amount of film from one chamber operating for one week.
} 


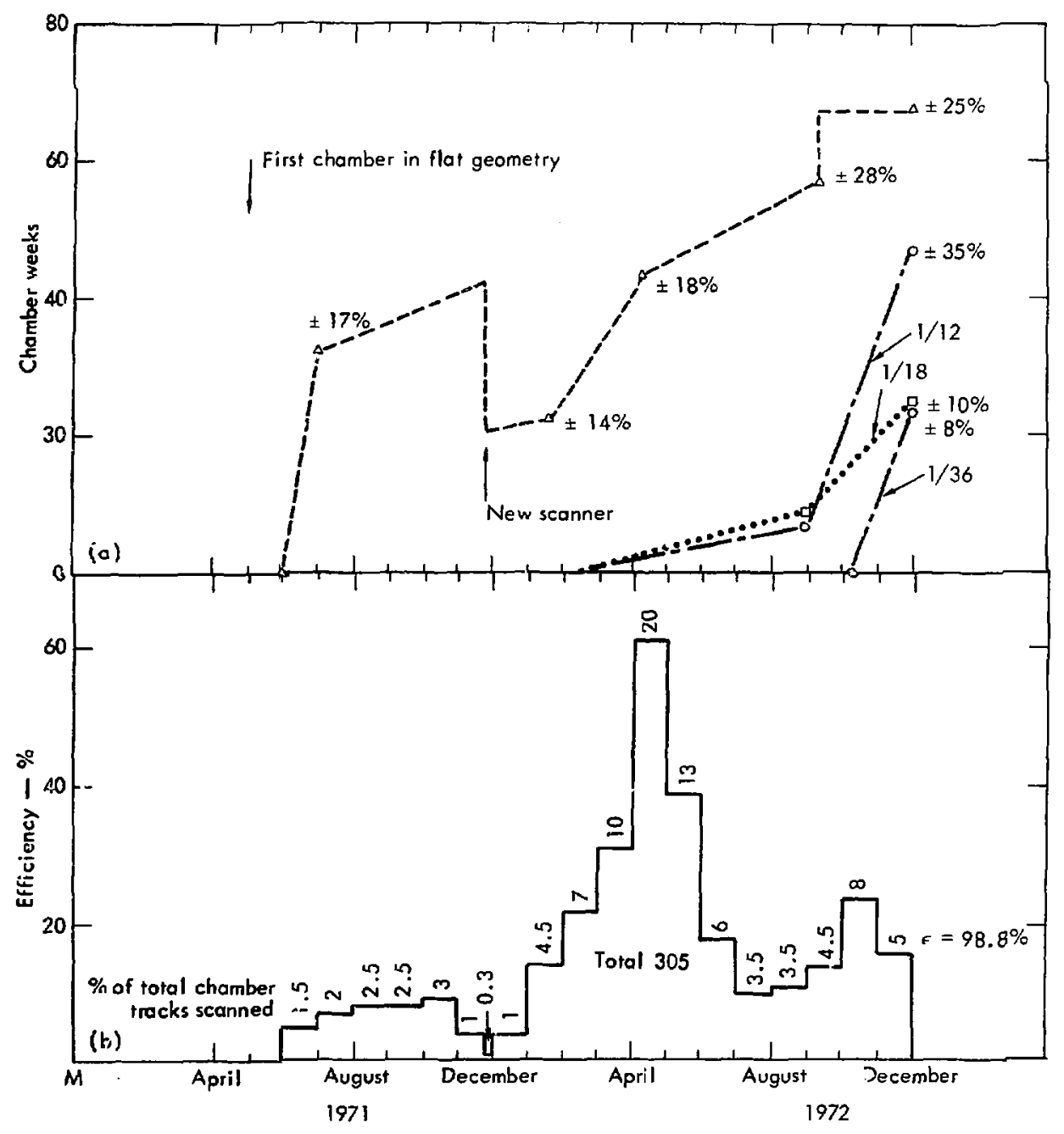

Fig. 2. (a) Scanner's efficiency versus time, and (b) chamber weeks scanned versus time. In (a), the slope of the line from $33 \% \pm 17 \%$ to $42 \%$ was assumed because there was no point at $42 \%$; also the scanner was still learning, as noted in later data. Also assumed were the slopes of the lines from the new scanner to $22 \% \pm 14 \%$ and from $57 \% \pm 28 \%$ to $67 \% \pm 25 \%$. 
First, the angle at which the track came into the chamber versus efficiency

(a)

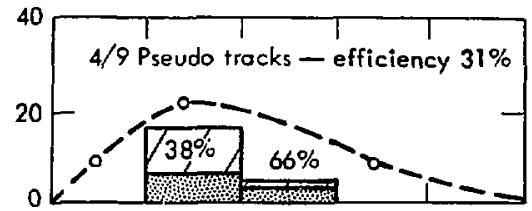

(b)

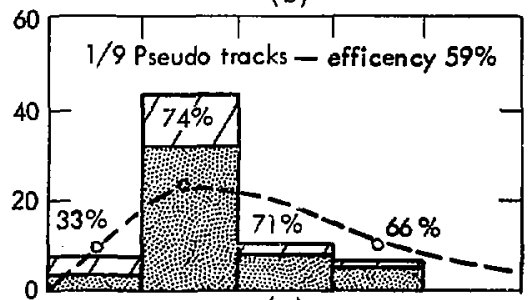

(c)

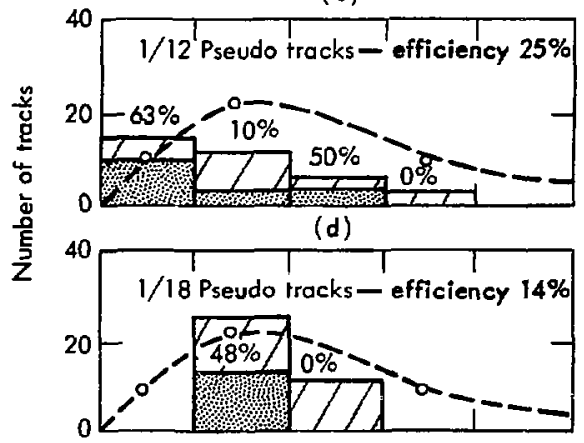

(e)

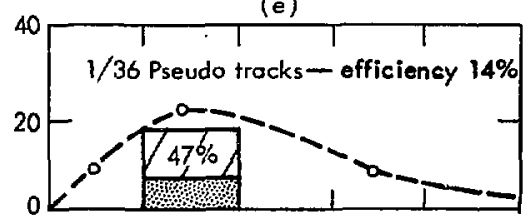

(f)

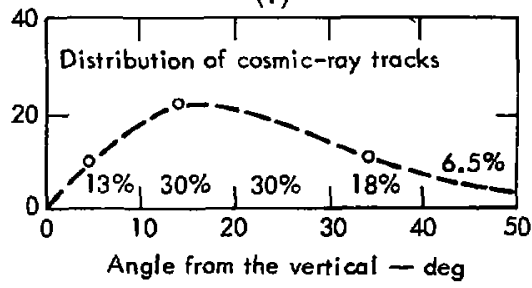

in finding these tracks was computed (Fig. 3). Thus, for example, in Fig. 3(b), the percentage of discovered 1/9 normal artificial tracks having a mocked-up foreshortening corresponding to zenith angles between $10^{\circ}$ and $20^{\circ}$ is $74 \%$. The find-rates represented in each of the histograms of Figs. 3(a) through $3(\mathrm{e})$ are then multiplied by the percentage of cosmic-ray tracks having the corresponding zenith angles, as given in Fig. $3(f)$. In our example, the percentage of tracks having zenith angles between $10^{\circ}$ and $20^{\circ}$ is $30 \%$. The efficiency thus derived is listed in the figures for each kind of track; for $1 / 9$ normal tracks [Fig. 3(a)] the efficiency so derived is $59 \%$. This type of analogy was done (witt respect to time) for each data point on the graph in Fig. 2(a). Note in Fig. 3 that in the lower density tracks ( $1 / 18$ and $1 / 36)$, data from both the low and the high angles were not taken. The reason for this was that the tracks that lay in these regions already approach

Fig. 3. (a-e) Efficiencies for tracks with droplet $/ \mathrm{cm}$ counts ranging down from $4 / 9$ normal (2e/3) to $1 / 36$ normal $(e / 6)$ are presented as a function of the steepness of the tracks in the chambers. The total number of tracks present is the sum of the shaded and cross-hatched areas in the histograms. The number of tracks found, given in percent at the top of each bar, is indicated by the shaded area. (f) The distribution of extensive air showers versus zenith angle. 
the limits of the experiment (efficiency $\approx 0$ ); therefore, the lower angle, low-density tracks were too short and appeared as just a blob, and the high-angie, lowdensity tracks became too long and contained too few drops per centimeter and faded into the chamber background. Some tracks in these regions were superimposed on the chamber, but could not be located even when we knew which frame they were in; therefore, the assumption was a good one that the scanning efficiency at these points should be zero.

Second, the amount of film scanned by the scanner versus time was piotted [Fig. 2(b)]. With this information, one can now obtain a number that gives the effective scan time used to find $1 / 9,1 / 12$, $1 / 18,1 / 36$ normal density tracks in cosmic-ray showers. To get the efficiencies, one would multiply the efficiency each week by the amount of film scanned with various efficiencies. The relative average efficiencies for finding $1 / 9,1 / 12$, $1 / 18,1 / 36$ densities are $45 \%, 6.5 \%, 5.4 \%$, $1.2 \%$ respectively.

The efficiency for finding 1/36 density tracks must be multiplied by another factor $(3 \%)$ because the only tracks at this low density that the scanner could find were those which had a blob of more than 30 droplets in view. The probability that a $1 / 36$ density track would have such a blob is $3 \%$. All tracks used in the efficiency number quoted above (for the $1 \%$ ) had such a blob.

This technique has made it possible to push the limits ${ }^{3}$ on finding $1 / 9$ quark-like tracks in cloud chambers to $2 \times 10^{-11}$ particles $\mathrm{cm}^{-2} \mathrm{sec}^{-1} \mathrm{sr}^{-1}$ and add new dimensions in the limits of finding lightdensity tracks in cloud chambers of $1 / 12$, $1 / 18$, and $1 / 36$ of normal density with limits of $8 \times 10^{-11}, 5 \times 10^{-10}, 7 \times 10^{-10}$, and $1 \times 10^{-7}$ particles $\mathrm{cm}^{-2} \mathrm{sec}^{-1} \mathrm{sr}^{-1}$ respectively.

\section{Acknowledgments}

I wish to express my gratitude to

Dr. Arnold F. Clark for his helpful discussions as well as his continuous guidance throughout.

I would like to thank Norman E. Hansen for his encouragement.

Also, a special thanks to Evelyn Faries for her patience, enthusiasm, and assistance in helping me obtain the data necessary for this report. 


\section{References}

1. R. D. Ernst, Pseudo Cloud Chamber Tracks and Their Uses, Lawrence Livermore Laborator:, Rept. UCRL-5,214 (1972).

2. A. F. Clark, R. D. Ernst, H. F. Finn, G. G. Griffis, N. E. Hansen, D. E. Smith, and W. Powell, Phys. Rev. Lett. 23, 658 (1969).

3. A. F. Clark, R. D. Ernst, H. F. Finn, G. G. Griffin, N. E. Hansen, D. E. Smith, "On the Lack of Fractionally Charged Particles in Cosmic Radiation," Phys. Rev. Lett., submitted Feb. 22, 1973. 